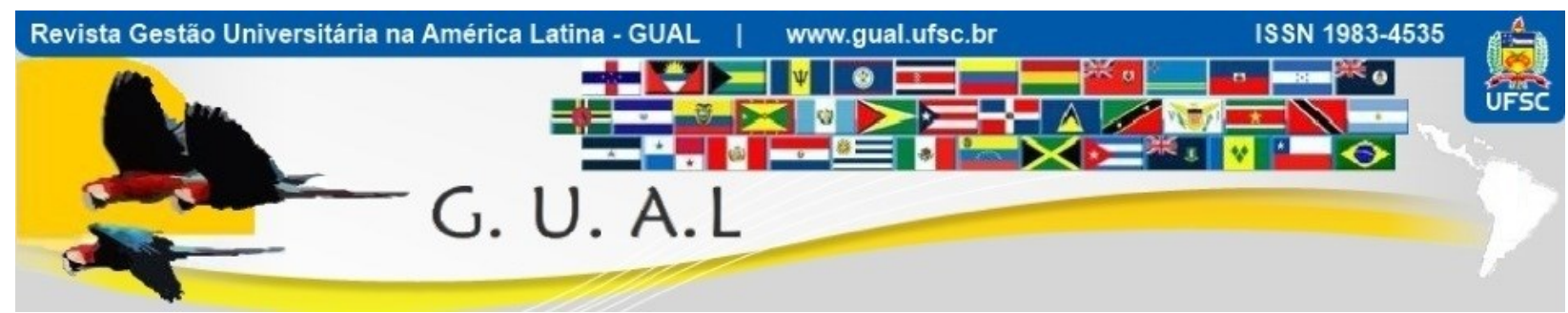

DOI: http://dx.doi.org/10.5007/1983-4535.2018v11n4p210

\title{
A EVASÃO APARENTE ENTRE ENGENHARIAS SOB A ÓTICA DA ANÁLISE DE REDES SOCIAIS
}

\section{APPARENT DROPOUT AMONG ENGINEERING STUDENTS USING SOCIAL NETWORK ANALYSIS}

Newton da Silva Miranda Júnior, Mestre

Universidade de Brasília - UnB newtonjr@unb.br

Andrea Felippe Cabello, Doutora Universidade de Brasília - UnB andreafc@unb.br

Valmir Emil Hoffmann, Doutor Universidade de Brasília - UnB ehoffmann@unb.br

Recebido em 24/novembro/2017

Aprovado em 06/setembro/2018

Sistema de Avaliação: Double Blind Review

Esta obra está sob uma Licença Creative Commons Atribuição-Uso. 


\title{
RESUMO
}

Embora muito se ressaltem as altas taxas de deserção acadêmica nos cursos de engenharia, as evasões aparentes pouco são evidenciadas, mesmo sendo parte do fenômeno. Dessa forma, o presente estudo aborda a evasão aparente entre habilitações da grande área de conhecimento das engenharias por meio da Análise de Redes Sociais - ARS. Como objetivo geral, descreveu-se essa rede por meio das métricas de densidade e grau de centralidade, analisandose o fluxo migratório dos 259 casos de transferências internas de alunos entre as 15 habilitações de engenharia, no período de 2012 a 2016, na Universidade de Brasília. Entre os resultados, a rede densa e os rumos dos fluxos migratórios entre os cursos sugerem uma propensão de o aluno de engenharia apenas mudar de habilitação entre as possíveis na instituição, permanecendo na área. As engenharias mecânica, elétrica e produção despontaram como as mais buscadas. Por outro lado, engenharias criadas mais recentemente na instituição tenderam a perder alunos dentro da rede. As evidências do estudo permitiram concluir que o aluno, embora incerto quanto à habilitação, possuiu a área de conhecimento como certa.

Palavras-chave: Ensino Superior. Evasão Aparente. Análise de Redes Sociais. Engenharias.

\begin{abstract}
Although high rates of academic dropout among engineering students are discussed, the socalled apparent dropout phenomenon does not get enough attention, even though they are part of the picture. Thus, the paper addresses this issue among engineering students, using a Social Network Analysis - ARS. As a general goal, we described this network through metrics such as density and degree of centrality, analyzing the migration of the 259 cases of internal transfers of students between 15 different types of engineering majors in the period ranging from 2012 to 2016 at the University from Brasilia. The dense network and the directions of the migratory flows between the courses suggest a propensity of engineering students to only change of habilitation within the field of engineering. Mechanical, electrical and production engineering have emerged as the most desired engineering careers. Also, the engineering careers created more recently at the university tended to lose students within the network. The evidences of the study allowed us to conclude that students, although uncertain about which type of engineering, have no doubts regarding the field of engineering.
\end{abstract}

Keywords: Higher education. Apparent evasion. Analysis of social networks. Engineering 


\section{INTRODUÇÃO}

Os estudos acerca evasão no ensino superior são numerosos, sendo expressiva a quantidade de publicações tanto na literatura internacional quanto nacional. Os modelos seminais mais utilizados foram propostos por Spady (1970) e Tinto (1975). Se desde a década em que tais estudos foram publicados a evasão já despontava como um problema a ser entendido e enfrentado, ainda hoje trata-se de um problema vivenciado por diversos cursos superiores, especialmente entre as engenharias (ALVES; MANTOVANI, 2016; SANTOS; LAGE JUNIOR; RIBEIRO, 2015).

O modelo do processo de abandono de Spady (1970 aborda, de modo geral, a decisão do aluno entre permanecer ou evadir de determinada Instituição, após ponderar os benefícios e custos de cada cenário. $O$ ato de permanecer na Instituição, contudo, não implica necessariamente continuar no mesmo curso de graduação em que se deu o ingresso. Por sua vez, o ato de evadir não significa o abandono do ensino superior. No primeiro caso, situa-se a mudança de curso dentro de uma mesma Instituição, por exemplo. A evasão, dessa forma, revela variadas facetas, como o abandono do ensino superior como um todo, a saída de uma determinda instituição ou a troca de um curso de graduação por outro, sendo esses dois últimos casos denominados como espécies de evasão aparente (VELLOSO; CARDOSO, 2008).

O modelo de Tinto (1975), por sua vez, associa a evasão no ensino superior à falta de integração do estudante ao sistema social e acadêmico da instituição. A integração está relacionada, sobremodo, ao grau de comprometimento do estudante e da instituição. Meyer e Marx (2014) citam o comprometimento do aluno como fator crucial à permanência na área das engenharias. Ao se considerar a evasão como saída definitiva sem conclusão do curso de origem ou pela perspectiva da consequente geração de vaga ociosa por tal desligamento, seja de um curso ou de uma instituição (ALVES; MANTOVANI, 2016), pode-se estar superestimando as taxas relacionadas a esse fenômeno, além de, conforme salientam Tosta, Abreu e Fornaciari (2016), possivelmente tratar de modo não diferenciado as espécies de evasão, conforme Lobo (2012): evasão de curso, evasão da instituição e evasão do sistema como um todo.

Em outras palavras, por não ser recorrente a distinção entre a evasão propriamente dita - abandono do ensino superior e a evasão aparente - saída de uma instituição ou troca de um curso por outro, observa-se, em alguns estudos, um descompasso entre a ocorrência de um 
subtipo com as causas associadas a ele, quando em verdade estão mais associadas a outros subtipos. Dessa forma, aquilo que genericamente se considera como evasão - propriamente dita, pode ser nada mais do que evasão aparente (VELLOSO; CARDOSO, 2008).

Neste interim, abordando a evasão aparente, o objetivo geral do presente estudo foi descrever e caracterizar a rede de mudanças de curso entre as habilitações em engenharia na Universidade de Brasília, no período entre o primeiro semestre de 2012 ao primeiro semestre de 2016, tendo como lócus de estudo a Universidade de Brasília. Foram abordados 259 casos distintos de transferência interna de alunos. Ademais, buscou-se analisar o efeito da política institucional de mudanças de curso na rede das engenharias e averiguar a influência da variável tempo de existência da habilitação sobre os fluxos migratórios de entradas e saídas de alunos entre os vértices da rede.

Entre as justificativas desse estudo, destaca-se o elevado e histórico índice de deserção acadêmica dentro da grande área de conhecimento das engenharias (RIOS; SANTOS; NASCIMENTO, 2001), assim como a necessidade de as intituições de ensino superior compreenderem melhor os fatores que contribuem à baixa permanência de alunos nessa grande área de conhecimento (MEYER; MARX, 2014). Ao se abordar a evasão de curso ou aparente, busca-se contribuir ao campo com evidências de que o aluno embora seja considerado evadido para as estatísticas oficiais, ele pode estar cursando outra habilitação na mesma instituição.

\section{FUNDAMENTAÇÃO TEÓRICA}

\subsection{FATORES ASSOCIADOS À EVASÃO ENTRE AS ENGENHARIAS}

A escolha por uma especialidade de engenharia não é tarefa fácil. Comparando à carreira médica, Shivy e Sullivan (2005) afirmam que o estudante interessado em cursar engenharia enfrenta o mesmo dilema daqueles estudantes de medicina que precisam optar por uma especilidade. A diferença, segundo essas autoras, é que o estudante de medicina tem a oportunidade de ter algum contato com as diversas especialidades durante o internato, diferentemente do estudante de engenharia cuja decisão pela especialidade deve ser anunciada na admissão (SHIVY; SULLIVAN, 2005).

Entre as consequências dessa escolha precipitada está a evasão, a qual implica em perdas de investimentos e de reputação para instituições de ensino (MOLLER-WONG; EIDE, 1997), prejuízos de ordem pessoal aos alunos (SHIVY; SULLIVAN, 2005), ociosidade entre 
docentes, funcionários, bem como de equipamentos e de espaço físico (SANTOS; LAGE JUNIOR; RIBEIRO, 2015).

As evasões entre as engenharias ocorrem, geralmente, nos períodos iniciais da graduação (SOUZA; LEITE; BITTAR, 2016; MEYER; MARX, 2014; MOLLER-WONG; EIDE et al., 1997), podendo-se, assim, ser caracterizada como prematura, conforme classificação de Lopera (2008). Tanto estudos internacionais quanto nacionais evidenciam esse ponto por meio dos mais variados métodos e técnicas de investigação. Pouco se relata, contudo, o destino desses alunos evadidos, tendendo-se a sublinhar somente as altas taxas de evasão entre as engenharias.

Os fatores associados à evasão nessa área do conhecimento são diversificados, sendo que englobam questões sócio-econômicas, institucionais e vocacionais e/ou pessoais (MEYER; MARX, 2014; REIS; CUNHA; SPRITZER, 2012). Entre as sócio-econômicas, podem ser citadas: inserção precoce no mercado de trabalho; a formação insuficiente em exatas; desempenho insatisfatório nas avaliações iniciais; mercado de trabalho desfavorável. Entre as institucionais: carga alta de estudos; mau relacionamento professor-aluno; corpo docente sem vocação para ensinar; ausência de matérias com aplicação prática; concentração excessiva de matérias básicas; estrutura insuficiente em laboratórios.

Por seu turno, entre as vocacionais ou pessoais, citam-se: baixo desempenho; escolha precipitada da carreira; falta de apoio familiar; não atendimento das expectativas dos estudantes por parte do curso; baixa motivação para estudar engenharia; desconhecimento dos aspectos concerntes ao curso de engenharia; incompatibilidade entre a carga exigida de estudos com afazeres pessoais, familiares e profissionais (SOUZA; LEITE; BITTAR, 2016; MEYER; MARX, 2014; PAURA; ARHIPOVA, 2014; REIS; CUNHA; SPRITZER,2012; SILVA; MAINIER; PASSOS, 2006; VASCONCELOS; ALMEIDA; MONTEIRO, 2009).

Não fica claro, entretanto, à qual espécie de evasão tais fatores se referem: abandono do ensino superior, saída da grande área de conhecimento das engenharias, mudança de habilitação dentro dessa área ou possível combinação dessas duas últimas espécies. Também é importante se considerar que o ingresso na área de engenharia não necessariamente corresponde à primeira opção ou ao interesse do estudante na área (SOUZA et al., 2016). Esses autores constataram, na universidade abordada por eles, a ocorrência de ingresso numa habilitação de engenharia motivado pela baixa concorrência do curso no Sistema de Seleção Unificada - Sisu. Vislumbra-se que, dessa forma, que o ingresso em alguma habilitação de engenharia também pode ser uma comportamento estratégico por parte do estudante. 
O Quadro 1 sintetiza os fatores associados à evasão entre as engenharias, segundo a literatura consultada.

Quadro 1 Fatores associados à evasão entre as engenharias

\begin{tabular}{|c|c|c|}
\hline \multicolumn{2}{|c|}{ Fatores associados à evasão nas engenharias } & Referências \\
\hline \multirow{2}{*}{ Sócio-econômicos } & Inserção precoce no mercado de trabalho & $\begin{array}{l}\text { Vasconcelos, Almeida e Monteiro } \\
\text { (2009); Curi, Neves e Barros (2010). }\end{array}$ \\
\hline & Formação insuficiente em exatas & $\begin{array}{l}\text { Silva, Mainier e Passos (2006); Reis, } \\
\text { Cunha e Spritzer (2012). }\end{array}$ \\
\hline Conjunturais & Mercado de trabalho desfavorável & Souza, Leite e Bittar (2016). \\
\hline \multirow{7}{*}{$\begin{array}{l}\text { Vocacionais o } \\
\text { pessoais }\end{array}$} & $\begin{array}{l}\text { Desconhecimento do programa das } \\
\text { engenharias }\end{array}$ & $\begin{array}{l}\text { Reis, Cunha e Spritzer (2012); Meyer e } \\
\text { Marx (2014); Souza, Leite e Bittar } \\
\text { (2016). }\end{array}$ \\
\hline & $\begin{array}{l}\text { Não atendimento das expectativas; } \\
\text { frustração com a área escolhida }\end{array}$ & $\begin{array}{l}\text { Reis, Cunha e Spritzer (2012); Meyer e } \\
\text { Marx (2014). }\end{array}$ \\
\hline & Escolha precipitada da carreira & Meyer e Marx (2014) \\
\hline & Ausência de apoio familiar & Souza, Leite e Bittar (2016) \\
\hline & $\begin{array}{l}\text { Falta de motivação para estudar } \\
\text { engenharia }\end{array}$ & Paura e Arhipova (2014) \\
\hline & Desempenho insatisfatório & $\begin{array}{l}\text { Reis, Cunha e Spritzer (2012); Meyer e } \\
\text { Marx (2014). }\end{array}$ \\
\hline & $\begin{array}{l}\text { Incompatibilidade com afazeres pessoais, } \\
\text { familiares e profissionais }\end{array}$ & Santos, Lage Junior e Ribeiro (2015) \\
\hline \multirow{6}{*}{ Institucionais } & Estrutura insuficiente dos laboratórios & Santos, Lage Junior e Ribeiro (2015) \\
\hline & $\begin{array}{l}\text { Incompatibilidade entre a carga de } \\
\text { estudos com afazeres pessoais, familiares } \\
\text { e profissionais }\end{array}$ & $\begin{array}{l}\text { Meyer e Marx (2014); Santos, Lage } \\
\text { Junior e Ribeiro (2015) }\end{array}$ \\
\hline & $\begin{array}{l}\text { Relacionamento professor-aluno } \\
\text { negativo }\end{array}$ & Silva, Mainier e Passos (2006) \\
\hline & Corpo docente sem vocação para ensinar & \multirow{3}{*}{ Souza, Leite e Bittar (2016) } \\
\hline & $\begin{array}{l}\text { Ausência de matérias com aplicação } \\
\text { prática }\end{array}$ & \\
\hline & $\begin{array}{l}\text { Concentração excessiva de matérias } \\
\text { básicas }\end{array}$ & \\
\hline
\end{tabular}

Fonte: pesquisa dos autores

\subsection{OS CURSOS DE ENGENHARIA NA UNIVERSIDADE DE BRASÍLIA}

A criação da Politécnica de Paris, em 1975, na França, foi o marco para a organização dos cursos de engenharia, especialmente no Brasil (OLIVEIRA, 2005). Inicialmente com tímida quantidade e contando com apenas habilitações tradicionais de engenharia na década de 1930, tais como civil, mecânica e elétrica (OLIVEIRA, 2005), a quantidade de cursos de engenharia no Brasil cresceu gradativamente. A formação em engenharia no Brasil passou por mudanças, sobremodo, a partir da década de 1980, deixando de ser focada apenas na vertente tecnológica e buscando ser mais abrangente ao envolver habilidade de gestão (OLIVEIRA, 2005; AMORIM, 2016). 
As primeiras engenharias da UnB foram criadas na década de 1970 nas seguintes habilitações: civil, elétrica, florestal e mecânica. Por outro lado, as habilitações mais recentemente criadas foram a aeroespacial e química. No total, são oferecidas atualmente 15 habilitações nas graduações voltadas à engenharia, ofertadas em dois campi: no campus Darcy Ribeiro, o central da UnB, e no campus Faculdade Gama (FGA). No primeiro campus são disponibilizadas as habilitações em: Ambiental, Civil, Computação, Produção, Redes De Comunicação, Elétrica, Florestal, Mecânica, Mecatrônica e Engenharia Química. Por seu turno, no campus FGA são oferecidas as habilitações em Aeroespacial, Automotiva, Energia, Software e Eletrônica.

Abordando a evasão e retenção nos cursos de engenharia de uma universidade pública federal brasileira, Rios, Santos e Nascimento (2001) argumentam em favor de um maior investimento no ciclo básico, haja vista a potencial contribuição para se diminuir a evasão nessa área de conhecimento. No contexto da UnB, há um ciclo básico de engenharia em todas as habilitações, composto por disciplinas generalistas envolvendo cálculo, física, química, entre outras necessárias à formação inicial. Todavia, no campus FGA esse ciclo básico é comum a todas as habilitações. Somente após cursado com aprovação é que o estudante encontra-se apto a escolher entre as habilitações ofertadas naquele campus. Ou seja, primeiro se cursa a formação básica e após se escolhe a habilitação. Diferentemente, no campus Darcy Ribeiro a habilitação já é escolhida na inscrição do vestibular ou SISu e, ocorrendo a aprovação para o curso, o aluno irá cursar a formação básica nele.

Em média, são necessários 258 créditos-aula para a formação em engenharia na UnB, sendo a quantidade máxima exigida para a habilitação em engenharia mecatrônica. Entre todas as habilitações, apenas engenharia de produção é ofertada no turno noturno, sendo as demais de período integral. A Tabela 1 apresenta as informações de todas as habilitações em engenharia da instituição abordada.

Tabela 1 Dados das habilitações em engenharia da UnB

\begin{tabular}{|l|c|c|c|}
\hline \multicolumn{1}{|c|}{ Curso de graduação } & Ano de criação & Turno & Créditos exigidos \\
\hline Engenharia Aeroespacial & 2012 & Diurno & 262 \\
\hline Engenharia Ambiental & 2010 & Diurno & 260 \\
\hline Engenharia Automotiva & 2008 & Diurno & 259 \\
\hline Engenharia Civil & 1979 & Diurno & 262 \\
\hline Engenharia de Computação & 2009 & Diurno & 252 \\
\hline Engenharia de Energia & 2008 & Diurno & 255 \\
\hline Engenharia de Produção & 2009 & Noturno & 240 \\
\hline $\begin{array}{l}\text { Eng. de Redes de } \\
\text { Comunicação }\end{array}$ & 1997 & Diurno & 250 \\
\hline Engenharia de Software & 2008 & Diurno & 240 \\
\hline
\end{tabular}




\begin{tabular}{|l|c|c|c|}
\hline \multicolumn{1}{|c|}{ Curso de graduação } & Ano de criação & Turno & Créditos exigidos \\
\hline Engenharia Elétrica & 1979 & Diurno & 262 \\
\hline Engenharia Eletrônica & 2008 & Diurno & 257 \\
\hline Engenharia Florestal & 1974 & Diurno & 258 \\
\hline Engenharia Mecânica & 1979 & Diurno & 262 \\
\hline Engenharia Mecatrônica & 1997 & Diurno & 274 \\
\hline Engenharia Química & 2012 & Diurno & 264 \\
\hline
\end{tabular}

Fonte: Sistema de graduação - SIGRA/UnB

\subsection{AS MUDANÇAS DE CURSO NA UNIVERSIDADE DE BRASÍLIA}

As mudanças de curso na Universidade de Brasília, definidas como a "autorização dada ao estudante regular de graduação para ter alterado o vínculo com seu curso de ingresso na Universidade para um curso de sua escolha" são regulamentadas pela Resolução do Conselho de Ensino, Pesquisa e Extensão - CEPE/UnB n. 138/2010.

De maneira geral, a mudança de curso via transferência interna não requer, no contexto da Universidade de Brasília, a realização de provas de conhecimentos. De modo geral, a seleção é realizada pela verificação de cumprimento de requisitos elencados nos editais e pela análise curricular dos inscritos.

As vagas disponíveis nos editais semestrais de mudança de curso, desmembradas nos turnos diurno e noturno quando o caso, são provenientes das vagas ociosas geradas no semestre anterior pelo não preenchimento das vagas ofertadas nos exames de seleção, a exemplo do vestibular e Sistema de Seleção Unificada - Sisu. Os editais também informam os requisitos e regras de admissibilidade à participação no processo. Nos editais correspondentes ao período analisado no presente estudo, para solicitar a mudança de curso de graduação, exigiu-se do aluno estar regularmente matriculado na universidade e cumulativamente:

a. Ter aprovação em disciplinas do curso de destino, obrigatórias ou optativas, no total de 24 créditos;

b. Integralização das disciplinas dos dois primeiros períodos da grade curricular do curso de origem.

A seleção entre os candidatos é norteada por uma fórmula matemática que parte do desempenho do estudante nas disciplinas obrigatórias e optativas cursadas por ele no curso de destino, sendo que as obrigatórias possuem maior peso. $\mathrm{O}$ modelo adotado pela instituição permite que alunos transitem entre as grades curriculares de cursos diferentes daquele em que se dá o ingresso. O não atendimento dos requisitos listados implica em eliminação do candidato do processo de seleção de mudança de curso. Salienta-se também que a nota obtida quando da aprovação no exame de seleção de ingresso na instituição não é levada em 
consideração para nenhum fim no processo seletivo de mudança de curso, tampouco se o ingresso se deu por cotas ou não.

\section{METODOLOGIA}

O presente estudo de caso, de enfoque quantitativo, empregou a técnica da Análise de Redes Sociais - ARS com o objetivo geral de se descrever e caracterizar a rede de mudanças de curso entre as habilitações em engenharia na Universidade de Brasília, desmembrado nos específicos de se analisar o efeito da política institucional de mudanças de curso na rede das engenharias e averiguar a influência da variável tempo de existência da habilitação sobre os fluxos migratórios de entradas e saídas de alunos entre os vértices da rede.

Os dados analisados são de natureza secundária extraídos da página eletrônica da instituição e se referem ao período do primeiro semestre de 2012 ao primeiro semestre de 2016, abragendo uma amostra de 259 casos distintos. Trata-se de mudanças de curso em que o processo seletivo ocorre internamente na instituição entre os estudantes que já possuem vínculo com algum curso de graduação e estavam regularmente matriculados. Ou seja, as mudanças de curso realizadas por meio de novos exames de seleção, a exemplo de vestibulares e Exame Nacional do Ensino Médio - ENEM, não foram consideradas.

A escolha da UnB se justifica pela considerável quantidade de habilitações em engenharias ofertadas por ela à sociedade, as quais somam 15, além de ser umas das principais instituiçpes de ensino superior do país. A análise de redes, assim como as métricas inerentes a ela, tais como densidade e grau de centralidade, foram realizadas com suporte dos programas Ucinet 6 e Netdraw, desenvolvidos por Borgatti, Everett e Freeman (2002). As demais análises recorreram à estatística descritiva. Em termos operacionais da abordagem em Análise de Redes Sociais, uma rede é composta por vértices e arestas. Os 16 vértices representaram as diferentes habilitações de engenharia e o ciclo básico em engenharia. As arestas, que conectam os vértices, simbolizaram as interações do fluxo migratório de entradas e saídas de alunos por meio das transferências internas. Os demais termos próprios da metodologia adotada de ARS são explicados no decorrer do estudo. 


\section{RESULTADOS}

\subsection{A REDE DE MUDANÇAS DE CURSOS ENTRE AS HABILITAÇÕES EM ENGENHARIA}

Nessa seção, objetivou-se descrever e caracterizar a rede de mudanças de curso entre as habilitações em engenharia na Universidade de Brasília. As seguintes perguntas de pesquisa nortearam essa etapa: Como ocorreram as interações entre as habilitações de engenharias via transferência interna? Qual foi a densidade e quais foram os vértices centrais da rede? O aluno oriundo de engenharia tendeu a permanecer ou abandonar a área de conhecimento das engenharias?

A rede de mudanças de cursos entre as habilitações em engenharia é apresentada na Figura 1. O tamanho diferenciado dos vértices indicam o fluxo líquido, obtido pela diferença entre a quantidade de entradas e a quantidade de saídas de alunos entre as habilitações de engenharia via transferência interna, conforme será informado mais adiante na Tabela 2. As arestas são assimétricas, isto é, o a quantidade de alunos que saíram de um curso A rumo ao curso $\mathrm{B}(\mathrm{A} \rightarrow \mathrm{B})$ não corresponde, necessariamente, à quantidade de saídas de $\mathrm{B}$ em direção a $A(B \rightarrow A)$. As cores subdividem os vértices em dois grupos: as engenharias com quantidade de entradas maior que saídas (azul escuro) e as engenharias em que a quantidade de saídas superou a de entradas (azul claro), conforme Figura 1.

Figura 1 Rede de mudanças de cursos entre as habilitações das engenharias (1\%/2012 ao 1\%/2016)

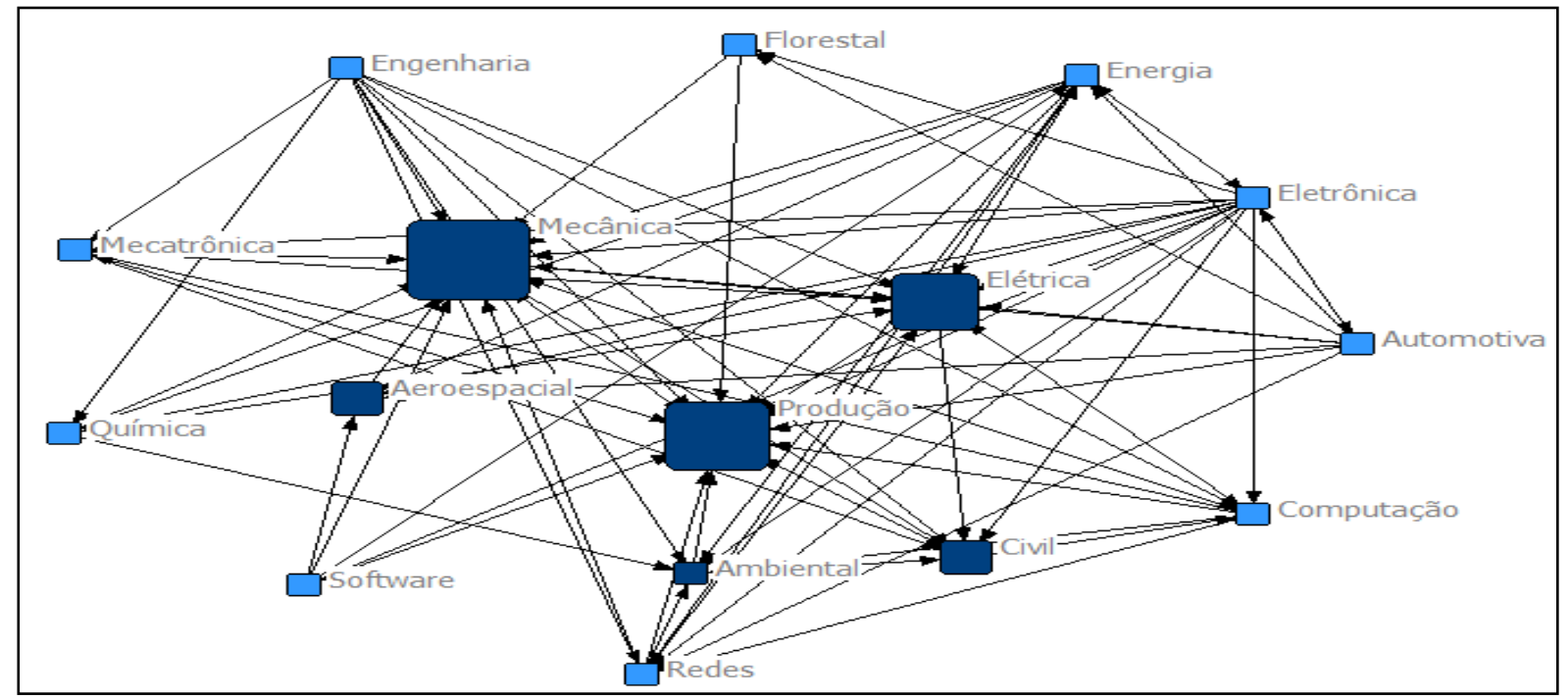

Fonte: dados da pesquisa 
Entre todos os 259 alunos que saíram de alguma habilitação em engenharia via transferência interna no período analisado, 215 (83\%) tiveram como destino alguma outra habilitação na própria área de conhecimento das engenharias. Para se caracterizar as ligações entre os vértices da rede, procedeu-se ao cálculo da métrica densidade. Trata-se de uma métrica que calcula a razão entre as ligações existentes em relação às potenciais entre os vértices de uma rede (PRELL, 2012). Operacionalmente, antes do cálculo dessa métrica, procedeu-se à dicotomização dos dados, conforme sugerido por Everton (2012). O valor encontrado foi de, aproximadamente, 33\%. Esse valor indica que entre as ligações potenciais da rede, mais de um terço delas foram estabelecidas, isto é, pode-se dizer que a rede é densa.

Esses resultados sinalizam que os fluxos de transferências internas de alunos entre as habilitações em engenharias existe e é expressivo, o que deixa a entrever que, diante a oportunidade de mudança de curso de graduação, o aluno de engenharia tende a permanecer na área. Essas evidências tornam menos rígidos os argumentos de que o abandono de engenharia se dá, sobremodo, por dificuldades de acompanhamento das disciplinas básicas dessa área de conhecimento (BRESSAN; MÓDOLO, 2011).

No intuito de se verificar se as interações na rede das engenharias se deram dispersamente entre as variadas habilitações ou de maneira concentrada em algumas delas, calculou-se o grau de centralidade, que é uma métrica voltada a apurar a variedade de vértices com os quais um dado vértice interage (EVERTON, 2012). Essa interação, na rede de mudanças de cursos entre as engenharias, poderia ser de dois tipos: pelo recebimento de alunos provenientes de outras habilitações - centralidade de entrada, ou pela perda de alunos para outras habilitações - centralidade de saída. A centralização encontrada da rede para o grau de entradas de 57,3\% e para o grau de saídas de 64,4\%. Embora a diferenção entre esses números não seja significativa, pode-se dizer que os fluxos migratórios de entradas são mais concentrados do que os de saídas, sendo, assim, indícios iniciais de que há preferências por determinadas habilitações entre os alunos transferidos internamente na rede analisada.

$\mathrm{Na}$ Tabela 2 são informados as quantidades de entradas e de saídas no acumulado bruto do período estudado, assim como o fluxo líquido (quantidade de entradas - quantidade de saídas). Também são informados os graus de centralidade e de saída, expressos em termos de quantidade de origens (número de cursos distintos de onde vêm os alunos) e quantidade de destinos (número de cursos distintos para onde vão os alunos). Por fim, na última coluna é informado o acumulado de vagas ociosas ofertadas no período analisado pelas diferentes engenharias. 
Tabela 2 Fluxo líquido e Grau de Centralidade de entrada e saída dos vértices da rede das engenharias

\begin{tabular}{|c|c|c|c|c|c|c|c|}
\hline \multirow[b]{3}{*}{ Cursos de graduação } & \multicolumn{3}{|c|}{ Fluxo líquido } & \multicolumn{4}{|c|}{ Grau de centralidade } \\
\hline & \multirow[b]{2}{*}{ 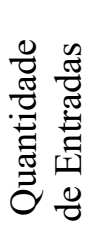 } & \multirow[b]{2}{*}{ 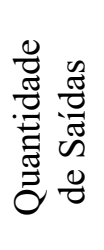 } & \multirow[b]{2}{*}{ 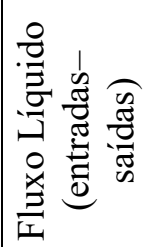 } & \multicolumn{2}{|c|}{ Entradas } & \multicolumn{2}{|c|}{ Saídas } \\
\hline & & & & 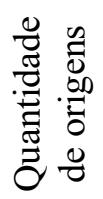 & 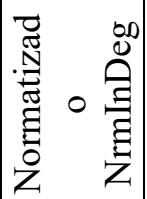 & 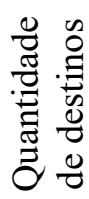 & 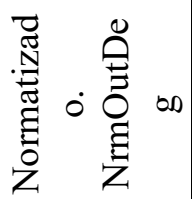 \\
\hline Engenharia (ciclo básico)* & 0 & 45 & -45 & 0 & 0 & 9 & 60.000 \\
\hline Engenharia Aeroespacial & 7 & 1 & 6 & 4 & 26.667 & 1 & 6.667 \\
\hline Engenharia Ambiental & 6 & 3 & 3 & 7 & 46.667 & 2 & 13.333 \\
\hline Engenharia Automotiva & 2 & 25 & -23 & 1 & 6.667 & 8 & 53.333 \\
\hline Engenharia Civil & 15 & 6 & 9 & 7 & 46.667 & 3 & 20.000 \\
\hline Engenharia de Computação & 9 & 12 & -3 & 5 & 33.333 & 6 & 40.000 \\
\hline Engenharia de Energia & 4 & 26 & -22 & 4 & 26.667 & 8 & 53.333 \\
\hline Engenharia de Produção & 48 & 5 & 43 & 13 & 86.667 & 3 & 20.000 \\
\hline Engenharia de Redes & 7 & 12 & -5 & 5 & 33.333 & 4 & 26.667 \\
\hline Engenharia de Software & 5 & 5 & 0 & 1 & 6.667 & 4 & 26.667 \\
\hline Engenharia Elétrica & 43 & 7 & 36 & 9 & 60.000 & 4 & 26.667 \\
\hline Engenharia Eletrônica & 3 & 26 & -23 & 2 & 13.333 & 14 & 93.333 \\
\hline Engenharia Florestal & 2 & 5 & -3 & 2 & 13.333 & 2 & 13.333 \\
\hline Engenharia Mecânica & 57 & 7 & 50 & 12 & 80.000 & 4 & 26.667 \\
\hline Engenharia Mecatrônica & 5 & 23 & -18 & 4 & 26.667 & 4 & 26.667 \\
\hline Engenharia Química & 2 & 7 & -5 & 3 & 20.000 & 3 & 20.000 \\
\hline
\end{tabular}

Fonte: elaborado pelos autores a partir dos dados da pesquisa

O curso com maior grau de centralidade de entrada na rede foi engenharia de produção, com grau normatizado de 86.667. De todas as possibilidades entre os vértices da rede, apenas duas habilitações de engenharia não registraram perda de alunos para engenharia de produção via transferência interna no período analisado: aeroespacial e química. Equivale a dizer que da variedade de habilitações em engenharia listadas, $86,6 \%$ delas perderam alunos para engenharia de produção. Essa habilitação destacou-se também por, embora tenha sido criada na instituição há menos de uma década, foi bastante demanda entre os candidatos à mudança interna de curso.

Afora o interesse pela habilitação em produção estar possivelmente relacionado ao fato de esse curso proporcionar conhecimento técnico, científico e de gestão (BITTENCOURT; VIALI; BELTRAME, 2010), outros fatores tornam essa habilitação peculiar na instituição abordada. Considerando que entre os motivos apontados por Barbosa, Mezzomo e Loder (2011) para a evasão de alunos de engenharia estava a frustração com a tentativa de ajuste de horário, o maior fluxo de alunos em direção a engenharia de produção 
talvez pode estar relacionado ao fato de ser a única habilitação ofertada pela UnB no turno noturno. Conforme Curi, Neves e Barros (2010), ao longo da formação acadêmica é natural que haja ingresso no mercado de trabalho, o que potencialmente pode prejudicar o rendimento acadêmico ou a dificuldade em compatibilizar a grade horária do curso com a jornada de trabalho.

No que concerne à centralidade de saída (ver Tabela 2), o maior valor foi observado em engenharia eletrônica, com o grau de centralidade de saída normatizado de 93.333. Equivale a dizer que engenharia eletrônica interagiu com 93,3\% dos vértices da rede, ou seja, perdeu alunos via transferência interna para a totalidade das demais engenharias, com exceção apenas dela mesma e a formação básica em engenharia, o que não faria sentido. Esses resultados deixam a entrever que o aluno que mudou de curso tendo como origem engenharia eletrônica, embora indecido quanto a esse curso, tinha como certa a grande área de conhecimento das engenharias, sendo possível também se imaginar que o aluno transferido preferia qualquer outra habilitação que não eletrônica. O destino mais recorrente desses alunos foi engenharia elétrica, o que leva-se a acreditar que, por eletrônica ser uma especialização de elétrica (OLIVEIRA et al., 2013), os alunos transferidos daquele curso tenham preferido uma formação mais generalista, a exemplo dessa última.

De modo geral, e ainda de acordo com a Tabela 2, há dois grupos de cursos entre os vértices da rede das engenharias: aqueles em que a quantidade de entradas de alunos via transferência interna foi menor que a quantidade de saídas (resultado líquido negativo) e aqueles com quantidade de entradas maior do que a de saídas (resultado líquido positivo). As habilitações de engenharia com maiores resultados negativos foram, respectivamente, automotiva (-23), eletrônica (-23) e energia (-22), ao passo que as habilitações com maiores resultados positivos foram, respectivamente, mecânica (50), produção (43) e elétrica (36).

Salienta-se o resultado obtido para a Engenharia - formação básica (-45), a qual é ofertada no campus FGA. Embora não se trate de um curso de graduação, optou-se por incluir os dados relativos a ela nesse estudo, haja vista que se observou uma migração considerável de alunos oriundos dela rumo às engenharias ofertadas no campus Darcy Ribeiro. Em números, essa migração foi observada em 46 casos, $21 \%$ do total de 215 mudanças de curso entre os vértices da rede das engenharias. Esses valores levam a se entrever a possibilidade de ocorrência de efeito trampolim. Em geral, as engenharias do campus Darcy Ribeiro são mais concorridas nos exames de seleção do que aquelas da FGA e, dessa forma, poderia estar havendo comportamento estratégico por parte do estudante: ingresso em cursos menos 
concorrido visando a permuta ao curso desejado (BRASIL, 1997; CUNHA; TUNES; SILVA, 2001).

\subsection{O EFEITO DA POLÍTICA INSTITUCIONAL DE MUDANÇAS DE CURSO NA REDE DAS ENGENHARIAS}

A finalidade da política institucional de mudanças de curso no âmbito da Universidade de Brasília, conforme editais abordados nesse estudo, foi preencher as vagas ociosas geradas nos semestres anteriores. Como se trata de uma política envolvendo apenas estudantes já vinculados a algum curso de graduação da instituição, é notável que, metaforicamente, as mudanças de curso representam uma espécie de dança das cadeiras. Em outras palavras, o quantitativo de vagas ociosas pode oscilar para mais, em caso de o curso ter mais abandonos do que ingressos, ou para menos, quando há menos abandonos do que ingressos de estudantes via transferência interna.

Com o objetivo de se analisar o efeito da política institucional de mudanças de curso na rede das engenharias, apurou-se o saldo de vagas ociosas de cada vértice da rede e, na sequência, da rede como um todo. Diferentemente dos dados referentes às interações da rede das engenharias, nessa seção os dados se referiram às interações entre todos os 77 cursos de graduação participantes da política institucional de mudança de curso. Para ser considerado participantes, bastava o curso ter ofertado alguma vaga em algum dos editais do período analisado nesse estudo.

Assim, essa seção foi norteada, sobremodo, pelas seguintes perguntas de pesquisas: $A$ rede de engenharias, em sua totalidade, amenizou ou agravou seu quadro de vagas ociosas com a política institucional de mudanças de curso? Quais áreas do conhecimento interagiram com área das engenharias e como se deu o impacto desse fluxo migratório de ingresso e saída de alunos em cada habilitação? Não obstante, há algum padrão nesses fluxos migratórios em relação ao tempo de existência das habilitações na instituição? Inicialmente, apresenta-se a Tabela 3, em que é informada a quantidade de vagas antes e após as mudanças de curso, no período de abrangência desse estudo, para as habilitações de engenharia da UnB.

Conforme se percebe pelo total agregado de vagas antes e após as mudanças de curso, houve uma redução de 2,5\% das vagas ociosas na área das engenharias. Equivale a dizer que o efeito da política institucional de mudanças de curso foi, de modo geral, positivo para a área 
das engenharias, havendo mais entradas do que saídas de alunos dessa área em relação às demais.

Tabela 3 Vagas ociosas antes e após as mudanças de curso entre os vértices da rede das engenharias

\begin{tabular}{|c|c|c|c|}
\hline \multirow{2}{*}{ Cursos de graduação } & \multicolumn{3}{|c|}{$\begin{array}{l}\text { Total de vagas ociosas } \\
\text { (acumulado do período } 1^{\circ} / 2012 \text { ao } 1^{\circ} / 2016 \text { ) }\end{array}$} \\
\hline & Antes $(*)$ & Após $(* *)$ & Variação \\
\hline Engenharia (ciclo básico)* & 164 & 210 & $28 \%$ \\
\hline Engenharia Aeroespacial & 61 & 56 & $-8,2 \%$ \\
\hline Engenharia Ambiental & 112 & 109 & $-2,7 \%$ \\
\hline Engenharia Automotiva & 60 & 85 & $41,7 \%$ \\
\hline Engenharia Civil & 31 & 15 & $-51,6 \%$ \\
\hline Engenharia de Computação & 95 & 96 & $1,1 \%$ \\
\hline Engenharia de Energia & 65 & 87 & $33,8 \%$ \\
\hline Engenharia de Produção & 102 & 51 & $-50 \%$ \\
\hline Engenharia de Redes & 147 & 158 & $7,5 \%$ \\
\hline Engenharia de Software & 38 & 41 & $7,9 \%$ \\
\hline Engenharia Elétrica & 59 & 20 & $-66,1 \%$ \\
\hline Engenharia Eletrônica & 78 & 101 & $29,5 \%$ \\
\hline Engenharia Florestal & 123 & 126 & $2,4 \%$ \\
\hline Engenharia Mecânica & 112 & 47 & $-58 \%$ \\
\hline Engenharia Mecatrônica & 122 & 138 & $13,1 \%$ \\
\hline Engenharia Química & 69 & 62 & $-10,1 \%$ \\
\hline Total da rede das engenharias & 1438 & 1402 & $-2,5 \%$ \\
\hline
\end{tabular}

(*) Acumulado de vagas não preenchidas nos exames de seleção - a exemplo de vestibulares e Sisu e, por conseguinte, ofertadas nos editais de mudanças de curso.

(**) Saldo de vagas obtido após o resultado líquido (entradas - saídas) das mudanças de curso.

Fonte: elaborado pelos autores a partir dos dados da pesquisa

As áreas do conhecimento de Ciências Agrárias e Exatas registraram juntas o maior percentual $(86 \%)$ de evasões de aluno via transferência interna rumo às Engenharias, sendo Física e Matemática os cursos com maiores frequências de casos. Essas evidências vão ao encontro dos resultados do estudo de Portilho e Pedroza (2008) na UnB com alunos que evadiram do curso de Física, em que se constatou que o estudante estrategicamente ingressava nesse curso a fim de cursar disciplinas de exatas e melhor se preparar ao vestibular para uma vaga nas engenharias, o que pode ser denominado como efeito trampolim (BRASIL, 1997). Na sequência ficaram as áreas Artes, Ciências Humanas e Sociais Aplicadas (9\%) e Ciências Biológicas e da Saúde (5\%).

O destino mais recorrente dos alunos que abandonaram alguma habilitação da área das engenharias também foi Ciências Agrárias e Exatas (52\%). Entretanto, percebeu-se um relativo equilíbrio com a área de Artes, Ciências Humanas e Sociais Aplicadas (43\%). Na 
sequência com menor percentual ficou a área de Ciências Biológicas e da Saúde (5\%). Os cursos de graduação com maiores frequências foram Matemática, Administração e Economia.

Quanto ao impacto do fluxo migratório das transferências internas sobre cada uma das habilitações de engenharias, conforme a última coluna da Tabela 3, o maior preenchimento de vagas se deu em engenharia elétrica, com redução de $66,1 \%$, ao passo que em engenharia automotiva observou-se o maior crescimento de vagas ociosas, com aumento de 41,7\%. Significa dizer que se por uma lado a política institucional de mudanças de curso atingiu sua finalidade em algumas habilitações, por outro lado, o efeito para outras foi o inverso daquele esperado: maior número de vagas ociosas.

As engenharias consideradas como tradicionais por Oliveira (2005) foram as que mais se beneficiaram, no acumulado, pelo preenchimento das vagas ociosas. Além da habilitação em elétrica informada acima, na sequência estiveram mecânica e civil com reduções de, respectivamente, $58 \%$ e $51,6 \%$. Entre aquelas que sofreram o efeito oposto da finalidade da política institucional de mudança de curso, além da habilitação em automotiva já informada, também estiveram energia e eletrônica com, respectivamente, $33,8 \%$ e $29,5 \%$ de aumento de vagas ociosas.

Essas engenharias são, coincidentemente, ofertadas no campus FGA, o que se leva a entrever que talvez essas evasões possam estar relacionadas a fatores institucionais, conforme discutido na fundamentação teórica. Não obstante, buscou-se averiguar a influência da variável tempo de existência da habilitação sobre os fluxos migratórios de entradas e saídas de alunos transferidos internamente na UnB. Dessa forma, o gráfico de dispersão apresentado na Figura 2 exibe um panorama dos vértices pertencentes à rede das engenharias constratando a quantidade de entradas (eixo horizontal) e de saídas (eixo vertical), por meio de transferência interna, no acumulado do período analisado. As habilitações foram agrupadas entre aquelas com idade de criação na instituição próxima ao tempo de existência na UnB e aquelas criadas ao longo das últimas duas décadas, conforme legenda da Figura 2.

É possível se perceber que as engenharias criadas há mais tempo ficaram localizadas próximas ao eixo horizontal, o que significa que a quantidade de saídas delas, nos processos de transferência interna, foi no geral menor em relação às engenharias criadas mais recentemente na instituição. Retomando os dados presentes na Tabela 1, nota-se que quanto mais recente a criação do curso de graduação, maior tendeu a ser a evasão de curso por transferência interna no período analisado. Conforme ressaltado anteriormente, o curso de engenharia de produção se destaca entre aqueles com quantidades expressivas de entradas. 
Ademais, conforme salientado, a quantidade expressiva de ingressos na habilitação em produção pode estar associada ao fato de ser a única ofertada no período noturno.

Figura 2 Dispersão entre as quantidades de saídas e entradas entre os vértices da rede das engenharias

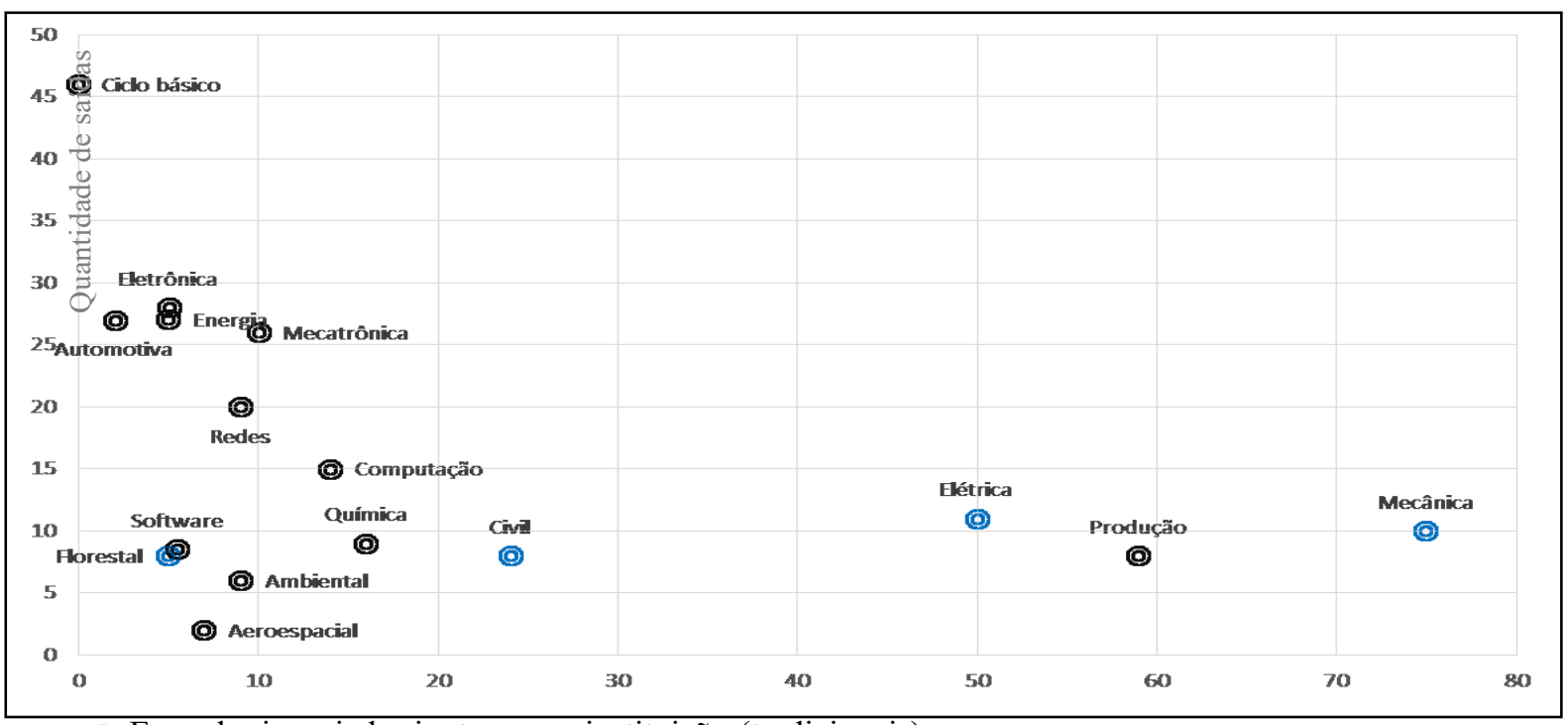

() Engenharias criadas junto com a instituição (tradicionais)

( ) Engenharias criadas recentemanete na instituição

Quantidade de entradas

Fonte: elaborado pelos autores a partir dos dados da pesquisa

\section{CONCLUSÃO}

A mudança de curso é, metaforicamente, uma dança das cadeiras no contexto da instituição abordada: ao mesmo tempo em que gera ociosidade também atua como mecanismo de preenchimento de vagas ociosas. Entretanto, nos dados da educação superior brasileira, a mobilidade acadêmica, de que é exemplo a mudança de curso, não é diferenciada da evasão real (VELLOSO; CARDOSO, 2008).

Um olhar para a mudança de curso tão somente como abandono do curso de origem pode levar à superestimação dos números que informam a evasão no ensino superior brasileiro, além de que deixa de lado a discussão acerca de um possível superdimensionamento da oferta de vagas no ensino superior (QUEIROZ; QUEIROZ, 2004) sendo que, quanto às engenharias, nos últimos anos tem se aumentado a quantidade de cursos acompanhado de crescente evasão (TOSTA; ABREU; FORNACIARI, 2016). Ademais, a mudança de curso pode ser vista também como processo de maturidade vocacional do estudante (MAGALHÃES; REDIVO, 1998; TERESA; SBARDELINI, 2001).

O presente estudo buscou descrever e caracterizar a rede de mudanças de curso entre as 15 habilitações em engenharia na Universidade de Brasília, as quais são ofertadas em dois 
distintos campi: Darcy Ribeiro e FGA. Constatou-se que se trata de uma rede densa permeada de insterações entre os vértices pertencentes a ela. Ou seja, o aluno de engenharia que mudou de curso via transferência interna na UnB no período entre o $1^{\circ} / 2012$ ao 1\%/2016 tendeu a permanecer na grande área do conhecimento das engenharias. Leva-se a concluir, por conseguinte, que embora houve dúvidas quanto à habilitação, o aluno estava seguro quanto à escolha pela área das engenharias.

As engenharias com maiores fluxos de ingressos de alunos foram as habilitações em Mecânica, Elétrica, Produção e Civil, respectivamente. Com exceção de engenharia de produção, as demais são tidas como formações tradicionais na área das engenharias, conforme Oliveira (2005). Conclui-se, dessa forma, que a maior busca por essas habilitações possa ser explicada pelo prestígio social ou talvez melhor alocação no mercado de trabalho. Por outro lado, os maiores fluxos de saída ocorreram em Automotiva, Eletrônica e Energia.

Embora Rios, Santos e Nascimento (2001) argumentam em favor de um maior investimento no ciclo básico, considerando-se a potencial contribuição dele na redução da evasão nas engenharias, constatou-se grande fuga de alunos da formação básica do campus FGA, via transferência interna, em direção às habilitações do campus Darcy Ribeiro. A recorrência desse fluxo migratório entre tais campi levou-se a considerar a ocorrência de comportamento estratégico do estudante: no intuito de estudar no campus Darcy Ribeiro, o ingresso no campus FGA, de menor concorrência nos exames de seleção, seria apenas uma ponte de acesso ou efeito trampolim.

Em relação ao objetivo específico de se analisar o efeito da política institucional de mudanças de curso na rede das engenharias, ficou evidenciado que de modo geral houve redução da quantidade de vagas ociosas nessa área do conhecimento no cenário pós mudanças de curso, no período analisado. Mais houve ingresso do que saída dessa área, de modo geral, devido a migração de alunos de Ciências Agrárias e Exatas para ela. Por outro lado, as saídas de alunos oriundos da área de engenharias, via transferência interna, ocorreu também rumo aos cursos de Ciências Agrárias e Exatas.

Quanto às habilitações, o efeito da política institucional de mudança de curso teve maior efeito na habilitação de Elétrica, a qual alcançou redução de 66,1\% de suas vagas ociosas geradas pelo não preenchimento de alunos aprovados em exames de seleção (a exemplo de vestibulares e Sisu). A habilitação em Automotiva, por outro lado, apresentou efeito oposto ao pretendido por aquela política: crescimento de vagas ociosas, com aumento de $41,7 \%$, devido à fuga de alunos desse curso via transferência interna no período analisado. 
Por fim, quanto ao último objetivo específico de se averiguar a influência da variável tempo de existência da habilitação sobre os fluxos migratórios de entradas e saídas de alunos entre os vértices da rede, ficou aparente uma preferência pelas habilitações mais tradicionais, ou seja, aquelas criadas há mais tempo na instituição. Entre as principais contribuições desse estudo estão os indícios de que a saída de uma engenheria não está condicionada, necessariamente, ao abandono dessa área de conhecimento, podendo ser apenas uma mudança de habilitação área. Nesse sentido, as evasões entre engenharias podem estar relacionadas à busca por melhores salários ou até mesmo identificação pessoal com outra habilitação (REIS; CUNHA; SPRITZER, 2012), considerando-se que devido à similaridade curricular estudantes podem perceber as habilitações da engenharia mais de maneira similar do que dissimilar (SHIVY; SULLIVAN, 2005).

Ademais, quanto aos fatores que relacionam o abandono nas engenharias à dificuldade de o aluno acompanhar as disciplinas da área, não parece ser uma verdade entre os casos abordados nesse estudo. Se assim fosse, esperar-se-ia, dessa maneira, que diante a oportunidade de migrar para uma outra área do conhecimento, o fluxo de evasão das engenharias seria bastante frequente. Hipótese essa não suportada pelos resultados desse estudo. Entre as limitações do estudo, salienta-se que foram analisadas somente as mudanças de cursos provenientes de transferência interna, não englobando possíveis alunos que mudaram de habilitação de engenharia por meio de novo exame de admissão. Como agenda de pesquisa, sugerem-se abordagens qualitativas com os alunos que optaram pela transferência interna, a fim de se conhecer fatores relacionados a tal decisão. Não obstante, apurar a evasão aparente nas demais instituições de ensino superior possibilitaria saber se os resultados aqui encontrados são projetáveis à área de conhecimento das engenharias ou uma realidade da instituição estudada.

\section{REFERÊNCIAS}

ALVES, M. F.; MANTOVANI, K. L. Identificação do perfil dos acadêmicos de engenharia como uma medida de combate à evasão. Revista de Ensino de Engenharia, v. 35, p. 26-36, 2016.

AMORIM, M. L. Qual Engenheiro? - Uma Análise dos Projetos Político-Pedagógicos dos Cursos de Engenharia da Universidade Tecnológica Federal do Paraná (UTFPR). Revista de Ensino de Engenharia, v. 35, n. 1, p. 25-35, 2016.

BARBOSA, P. V.; MEZZOMO, F.; LODER, L. L. Motivos de Evasão no Curso de Engenharia Elétrica: realidade e perspectivas. In: XXXIX Congresso Brasileiro de Educação em Engenharia, Blumenau. Anais... Blumenau: COBENGE, 2011. 
BITTENCOURT, H. R.; VIALI, L.; BELTRAME, E. A Engenharia de Produção no Brasil: um panorama dos cursos de graduação e pós-graduação. Revista de Ensino de Engenharia, v. 29, n. 1, p. 11-19, 2010.

BRASIL. Diplomação, retenção e evasão nos cursos de graduação em instituições de ensino superior públicas. Relatório da Comissão Especial de Estudos sobre Evasão nas Universidades Públicas Brasileiras. Brasília, DF: ANDIFES/ABRUEM/SESu/MEC, 1997.

BRESSAN, G. M.; MÓDOLO, D. L. Motivação para o ensino de disciplinas básicas nos cursos de engenharia. In: XXXIX Congresso Brasileiro de Educação em Engenharia, Blumenau. Anais... Blumenau: COBENGE, 2011.

CUNHA, A. M.; TUNES, E.; SILVA, R. R. Evasão do curso de química da Universidade de Brasília: a interpretação do aluno evadido. Química Nova, vol. 24, n. 1, pp. 262-280, 2001.

CURI, R. C.; NEVES, D. V.; BARROS, S. Evasão no curso de engenharia civil ocasionado pela dupla jornada de trabalho. In: XXXVII Congresso Brasileiro de Educação em Engenharia, Fortaleza. Anais... Fortaleza: COBENGE, 2010.

EVERTON, S. F. Disrupting dark networks. Naval Postgraduate School, Monterey, California. Cambridge, 2012.

LOBO, M. B. Panorama da Evasão no Ensino Superior Brasileiro: Aspectos Gerais das

Causas e Soluções. Associação Brasileira de Mantenedoras de Ensino Superior Cadernos, v. 25, p. $1-23,2012$.

LOPERA, C. Determinantes de la deserción universitaria en la Facultad de Economía Universidad del Rosario. Borradores de Investigación, v. 95, n. 26, 2008.

MAGALHÃES, M.; REDIVO, A. Re-opção de Curso e Maturidade Vocacional. Revista Brasileira de Orientadores Profissionais, v. 3, n. 1, p. 7-28, 1998.

MEYER, M.; MARX, S. Engineering dropouts: A qualitative examination of why undergraduates leave engineering. Journal of Engineering Education, v. 103, n. 4, p. 525$548,2014$.

MOLLER-WONG, C.; EIDE, A. An engineering student retention study. Journal of Engineering Education, v. 86, n. 1, p. 7-15, 1997.

OLIVEIRA, V. F. Crescimento, evolução e o futuro dos cursos de engenharia. Revista de Ensino de Engenharia, v. 24, n. 2, p. 3-12, 2005.

OLIVEIRA, V. F. et al. Um estudo sobre a expansão da formação em engenharia no Brasil. Revista de Ensino de Engenharia, v. 32, n. 3, 2013

PAURA, L.; ARHIPOVA, I. Cause Analysis of Students' Dropout Rate in Higher Education Study Program. Procedia - Social and Behavioral Sciences, v. 109, p. 1282-1286, 2014.

PORTILHO, O.; PEDROZA, A. C. Um estudo da evasão no curso de graduação em física da UnB. Relatório à comissão de graduação do Instituto de Física. Brasília: ago. 2008.

Disponível em: http://www.if.ufrgs.br/gra/agenda/relatorio_a_comissao_de_graduacao.pdf. Acesso em agosto de 2016.

PRELL, C. Social network analysis: history, theory \& methodology. Los Angeles: Sage, p. 263, 2012. 
QUEIROZ, F. C.; QUEIROZ, J. V. Acesso E Permanência No Ensino Superior Brasileiro Há Superdimensionamento Da Oferta? In: IV Colóquio Internacional sobre Gestão Universitária, Florianópolis, 2004. Anais... Florianópolis: CIGU, 2004.

REIS, V. W.; CUNHA, P. J.; SPRITZER, I. M. Evasão no ensino superior de engenharia no Brasil: um estudo de caso no CEFET/RJ. In: XL Congresso Brasileiro de Educação em Engenharia, Belém, 2012. Anais... Belém: COBENGE, 2012.

RIOS, J. R.; SANTOS, A. P.; NASCIMENTO, C. Evasão e Retenção no ciclo básico dos cursos de engenharia da Escola de Minas da UFOP. In: XXIX Congresso Brasileiro de Educação em Engenharia, Porto Alegre, 2001. Anais... Porto Alegre: COBENGE, 2001.

SANTOS, N. V.; LAGE JUNIOR, M. L.; RIBEIRO, M. L. Evasão no curso de engenharia de produção da Universidade Federal de Goiás - regional catalão. In: XXXV Encontro Nacional de Engenharia de Produção, Fortaleza, 2015. Anais... Fortaleza: ENEGEP, 2015.

SBARDELINI, E. T. Identidade profíssional e opção universitária. Psicologia Escolar e Educacional, Campinas, v. 5, n. 1, p. 91-93, 2001.

SHIVY, V. A.; SULLIVAN, T. N. Engineering students' perceptions of engineering specialties. Journal of Vocational Behavior, v. 67, p. 87-101, 2005.

SILVA, R. R.; MAINIER, F. B.; PASSOS, F. B. A contribuição da disciplina de introdução à engenharia química no diagnóstico da evasão. Ensaio: avaliação de políticas públicas em educação, Rio de Janeiro, v. 14, n. 51, p. 261-277, 2006.

SOUZA, C. C.; LEITE, J. P.; BITTAR, L. B. Evasão de discentes do curso de engenharia de petróleo da universidade federal fluminense. In: XLIV Congresso Brasileiro de Educação em Engenharia, Natal. Anais... Natal: COBENGE, 2016.

SPADY, W. G. Dropouts in higher education: an interdisciplinary review and synthesis. Interchange, v. 1, n. 1, p. 64-85, 1970.

TINTO, V. Dropout from Higher Education: a theoretical synthesis of recent research. Review of Educational Research, v. 45, n. 1, p. 89-125, 1975.

TOSTA, M. R.; ABREU, L. C.; FORNACIARI, J. R. Por que eles desistem? Análise da evasão no curso de Engenharia da Produção. In: XXXVI Encontro Nacional de Engenharia de Produção, João Pessoa, 2016. Anais... João Pessoa: ENEGEP, 2016.

VASCONCELOS, R.; ALMEIDA, L. S.; MONTEIRO, S. O insucesso e abandono académico na universidade : uma análise sobre os cursos de engenharia. In: VI International Conference on Engineering and Computer Education, Buenos Aires, 2009. Anais... Buenos Aires: ICECE, 2009.

VELLOSO, J.; CARDOSO, C. B. Evasão na Educação Superior: alunos cotistas e não cotistas na Universidade de Brasília. In: 31a Reunião Anual da Associação Nacional de PósGraduação e Pesquisa em Educação, Caxambu, 2008. Anais... Caxambu: ANPEd, 2008. 